\title{
Effectiveness of $p$-dopants in an organic hole transporting material
}

\author{
Jae-Hyun Lee, Dong-Seok Leem, ${ }^{\text {a) }}$ Hyong-Jun Kim, and Jang-Joo Kim ${ }^{\text {b) }}$ \\ Department of Materials Science and Engineering and the Center for OLED, Seoul National University, \\ Seoul 151-742, South Korea
}

(Received 24 December 2008; accepted 6 March 2009; published online 27 March 2009)

\begin{abstract}
We investigated the effectiveness of $p$-dopants to generate holes in a hole transporting material by comparing the absorption in visible-near-infrared and infrared regions and current density-voltage characteristics. $\mathrm{CuI}, \mathrm{MoO}_{3}$, and $\mathrm{ReO}_{3}$ having different work functions were doped in a hole transporting organic material, 4, $4^{\prime}, 4^{\prime \prime}$-tris( $\mathrm{N}$-(2-naphthyl)-N-phenylamino)-triphenylamine (2TNATA). Formation of charge transfer (CT) complexes increases linearly with increasing doping concentration for all the dopants. Dopants with higher work function $\left(\mathrm{ReO}_{3}>\mathrm{MoO}_{3}>\mathrm{CuI}\right)$ are more effective in the formation of $\mathrm{CT}$ complexes and in the generation of the charges in the doped films. (C) 2009 American Institute of Physics. [DOI: 10.1063/1.3107267]
\end{abstract}

Reducing the driving voltage in organic light emitting diodes and other organic electronic devices is important to reduce the power consumption. Doping in organic materials is an important technique to reduce the contact resistance between electrodes and organic materials, thereby to improve the power efficiency. Lithium, ${ }^{1}$ cesium, ${ }^{2}$ cesium carbonate $\left(\mathrm{Cs}_{2} \mathrm{CO}_{3}\right),{ }^{3}$ and rubidium carbonate $\left(\mathrm{Rb}_{2} \mathrm{CO}_{3}\right)$ (Refs. 4 and 5 ) have been commonly used as $n$-type dopants. Various kinds of $p$-type dopants have been developed, including organic dopant such as tetrafluoro-tetracyano-quinodimethane $\left(\mathrm{F}_{4}-\mathrm{TCNQ}\right),{ }^{6}$ metal halides such as antimony pentachloride $\left(\mathrm{SbCl}_{5}\right),{ }^{7}$ ferric chloride $\left(\mathrm{FeCl}_{3}\right)$ (Ref. 8) and copper iodide $(\mathrm{CuI}),{ }^{9}$ and metal oxides such as vanadium oxide $\left(\mathrm{V}_{2} \mathrm{O}_{5}\right),{ }^{10}$ tungsten oxide $\left(\mathrm{WO}_{3}\right){ }^{11}$ molybdenum oxides $\left(\mathrm{MoO}_{x}\right),{ }^{12,13}$ and rhenium oxide $\left(\mathrm{ReO}_{3}\right) .{ }^{14}$ Many groups presented that the $p$-dopants form charge transfer (CT) complexes with hole transporting organic materials by electron transfer from organic molecules to the dopant. However, there are few reports on the relative effectiveness of dopants in the formation of CT complexes and in generating charges.

In this letter, we report on the effectiveness of $p$-dopants in the formation of CT complexes and in generating charges by paying attention to the energy difference between the highest occupied molecular orbital (HOMO) level of organic materials and Fermi energy level of $p$-dopants $(\Delta E$ $\left.=E_{\mathrm{HOMO} \text {,host }}-E_{F, \text { dopant }}\right)$. CuI, $\mathrm{MoO}_{3}$, and $\mathrm{ReO}_{3}$ possessing different work functions $\left[\operatorname{ReO}_{3}(6.0 \mathrm{eV})>\mathrm{MoO}_{3}(5.7 \mathrm{eV})\right.$ $>\mathrm{CuI}(5.4 \mathrm{eV})]^{15-17}$ have been selected as the dopants and 4, 4', 4"-tris(N-(2-naphthyl)-N-phenylamino)-triphenylamine (2TNATA) as the host material. Based on the comparative study, we will clearly demonstrate that the dopant with larger energy difference will give higher concentration of CT complexes and carrier densities at same doping concentration. Therefore $\mathrm{ReO}_{3}$ is a more effective $p$-dopant than $\mathrm{MoO}_{3}$ or CuI.

Glass substrates with $150 \mathrm{~nm}$ thick patterned indium tin oxide (ITO) were used to fabricate devices after cleaning with acetone and isopropyl alcohol. The doped organic layers

\footnotetext{
${ }^{a)}$ Present address: Department of Physics, Imperial College-London, South Kensington, SW7 2AZ, United Kingdom.

b) Author to whom correspondence should be addressed. Electronic mail: jjkim@snu.ac.kr.
}

were formed by coevaporation of the dopants and the host in an evaporation chamber under $10^{-7}$ torr. The fabricated devices were encapsulated with a getter in the dry nitrogen glove box prior to the measurement. The current densityvoltage $(J-V)$ characteristics of the devices were measured by a Keithley 2400 semiconductor parameter analyzer. 50 and $100 \mathrm{~nm}$ thick doped 2TNATA films were evaporated on glass substrates for the ultraviolet-visible-near infrared (UVVis-NIR) absorption measurements and on Si wafers for the Fourier transform infrared (FT-IR) spectroscopy measurements, respectively. UV-Vis-NIR spectrophotometer (Cary 5000) and FT-IR spectrometer (JASCO FT/IR-660) were used for the optical measurements. The capacitance-voltage measurements were carried out by a 1260 impedance/gainphase analyzer and a 1287 electrochemical interface (Solartron).

The formation of CT complexes can be easily detected by appearance of additional absorption peaks in NIR region, which are not shown by either component. Figure 1(a) shows UV-Vis-NIR absorption spectra of an undoped host 2TNATA film and doped 2TNATA films with the three kinds of dopants at the same doping concentration of $25 \mathrm{~mol} \%$. The absorption spectrum of the undoped 2TNATA film shows only absorption by $\pi-\pi^{*}$ transition below the wavelength of $400 \mathrm{~nm}$ and background absorption including the scattering and optical interference of solid film on a glass substrate. In contrast, the absorption spectra of the doped 2TNATA films show additional absorption peaks at around 467 and 1226 $\mathrm{nm}$, demonstrating the formation of CT complexes. The dopants have the work functions in sequence of $\mathrm{ReO}_{3}>\mathrm{MoO}_{3}$ $>\mathrm{CuI}$ having 6.0, 5.7, and $5.4 \mathrm{eV}$, respectively. HOMO energy level and lowest unoccupied molecular orbital (LUMO) energy level of 2TNATA are 5.0 and $2.1 \mathrm{eV}$, which was measured by cyclic voltammetry and the absorption spectrum, respectively. Although there is probably no simple relationship between the Fermi level of a bulk semiconductor and the electron-accepting property of the same material dispersed in an organic host, it is reasonable to inquire whether the dopants form CT complexes with the 2TNATA. The absorbance of the CT complex peak near $1226 \mathrm{~nm}$ wavelength increases linearly with doping concentration in 2TNATA films for all the dopants as shown in Fig. 1(b). These linear increases in the CT complex peaks indicate that all the dop- 

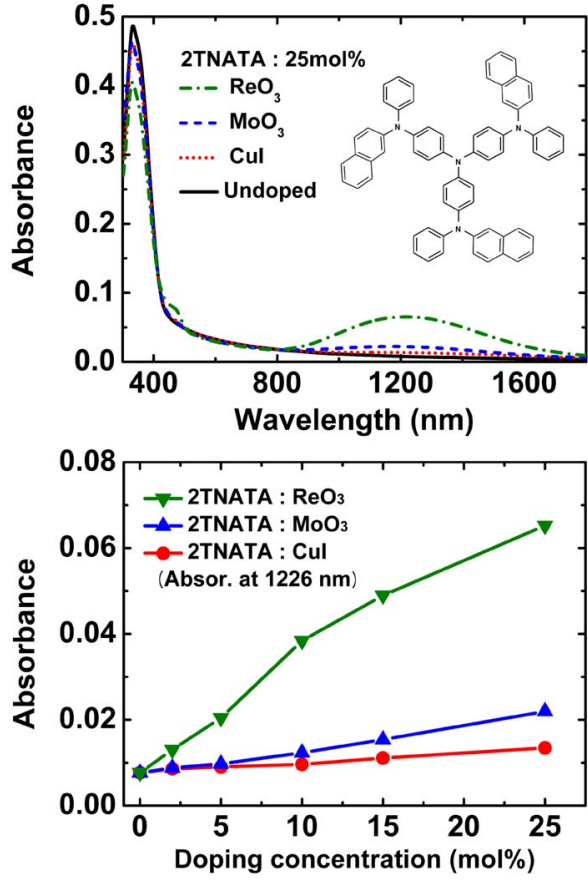

FIG. 1. (Color online) (a) UV-Vis-NIR absorbance spectra of doped (25 mol \%) 2TNATA films with $\mathrm{ReO}_{3}$ (dash-dotted curve), $\mathrm{MoO}_{3}$ (dashed curve), CuI (dotted curve), and undoped 2TNATA film (solid curve). Inset: the molecular structure of 2TNATA (b) absorbance of the second CT complex peak vs doping concentration for $\mathrm{ReO}_{3}$ (inverse triangle), $\mathrm{MoO}_{3}$ (triangle), and $\mathrm{CuI}$ (circle) doped 2TNATA films.

ant molecules contribute to the formation of the CT complex without saturation up to the doping concentration of $25 \mathrm{~mol} \%$. However, the effectiveness of the dopants in the formation of CT complexes is different for each dopant. $\mathrm{ReO}_{3}$ doped films show the highest CT complexation ability with 2TNATA followed by $\mathrm{MoO}_{3}$ and CuI. This complexation ability follows the same sequence as the energy difference of $\Delta E=E_{\text {HOMO,host }}-E_{F, \text { dopant }}$.

Formation of CT complexes is further confirmed by FT-IR measurements. CT from the 2TNATA molecule to the metal complex dopant will modify the charge distribution of the 2TNATA molecule and rearrange binding energy between the atoms in the molecule of the CT complex. ${ }^{18}$ In Fig. 2, doped 2TNATA films show additional absorption peaks at 1167 and $1567 \mathrm{~cm}^{-1}$, which are originated from the $\mathrm{C}=\mathrm{C}$ stretching bands of parasubstituted benzene group of the 2TNATA molecule at 1108 and $1497 \mathrm{~cm}^{-1} \cdot{ }^{19}$ It is confirmed by a molecular simulation through the density function

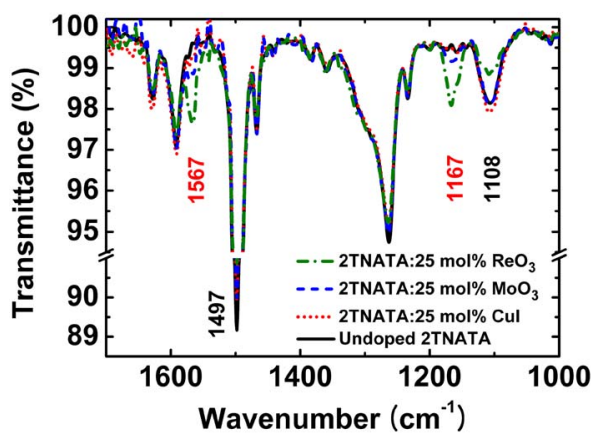

FIG. 2. (Color online) FT-IR spectra of doped 2TNATA films with $25 \mathrm{~mol} \% \mathrm{ReO}_{3}$ (dash-dotted curve), $\mathrm{MoO}_{3}$ (dashed curve), and $\mathrm{CuI}$ (dotted curve) and undoped 2TNATA film (solid curve).

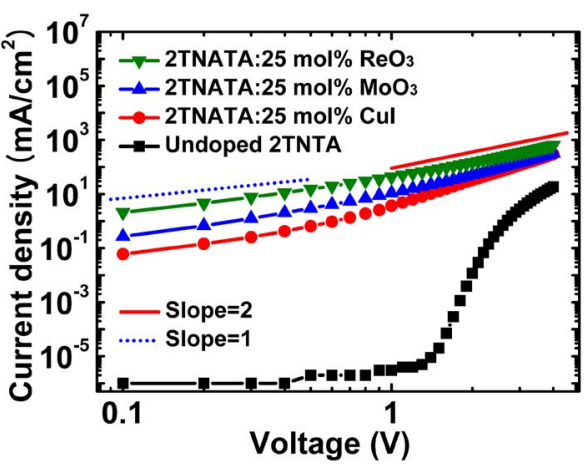

FIG. 3. (Color online) The $J-V$ characteristics of hole only devices fabricated using doped 2TNATA films with $25 \mathrm{~mol}_{\%} \mathrm{ReO}_{3}$ (inverse triangle), $\mathrm{MoO}_{3}$ (triangle), and CuI (circle), and undoped 2TNATA film (rectangle). Lines with the slope of 1 and 2 are shown for references.

theory calculations with the $\mathrm{Dmol}^{3}$ module installed Materials Studio (Accelrys) that the HOMO electron of the 2TNATA molecule is almost entirely located on the nitrogen atom and the parasubstituted benzene. The fact that three chemically different dopants show the same wave number shift of 59 and $70 \mathrm{~cm}^{-1}$, respectively, probably indicates that the 2TNATA molecules are full ionized by CT complexation with the three dopants. However, the degree of the formation of the CT complexes is different for dopants displayed by the different intensity of the additional peaks in the spectra. Again, the intensity and, therefore, the number of ionized 2TNATA molecules per the dopant molecule is the largest for $\mathrm{ReO}_{3}$, followed by $\mathrm{MoO}_{3}$ and $\mathrm{CuI}$.

The effect of doping on the charge transport was investigated using the hole only devices consisting of ITO/25 mol \% doped 2TNATA $(80 \mathrm{~nm}) / \mathrm{Ag}(50 \mathrm{~nm})$ structure and the $J-V$ characteristics of the devices are shown in Fig. 3. The doped devices exhibit much higher current density than the undoped device and displayed near Ohmic transport at low current density followed by the trap-free space charge limited current. The electrical conductivities of 2TNATA films doped with $25 \mathrm{~mol} \% \mathrm{ReO}_{3}, \mathrm{MoO}_{3}$, and $\mathrm{CuI}$ in the quasi-Ohmic region were calculated to be $2.0 \times 10^{-7}$, $3.3 \times 10^{-8}$, and $8.9 \times 10^{-9} \mathrm{~S} / \mathrm{cm}$, respectively. These enhanced current density and conductivity can be interpreted by increased carrier density. The carrier density was estimated by the capacitance-voltage $(C-V)$ measurement of the metal-insulator-semiconductor (MIS) devices. ${ }^{20,21}$ Using the standard Schottky-Mott analysis, the carrier density $N$ is calculated by the following equation: ${ }^{22}$

$$
N=\frac{2}{q \varepsilon_{0} \varepsilon_{r}}\left[\frac{1}{d\left(1 / C^{2}\right) / d V}\right],
$$

where $q$ is the charge of an electron, $\varepsilon_{0}$ is the permittivity of empty space, and $\varepsilon_{r}$ is the relative dielectric constant of doped films. The relative dielectric constant $\varepsilon_{r}$ is assumed to be 3.78 , which is measured from the device with undoped film. Figure 4 shows carrier density extracted from the slope of $\mathrm{C}^{-2}-\mathrm{V}$ plot of the MIS devices consisting of ITO/LiF (50 $\mathrm{nm}) /$ doped 2TNATA $(50 \mathrm{~nm}) / \mathrm{Ag}(50 \mathrm{~nm})$ layers, where the capacitance was measured at the frequency of $1 \mathrm{kHz}$ with the ac amplitude of $50 \mathrm{mV}$. The generated carrier density by the doping was increased with doping concentration for all the dopants. Once again, the $\mathrm{ReO}_{3}$ doped 2TNATA film showed the highest carrier density among the three dopants. The 


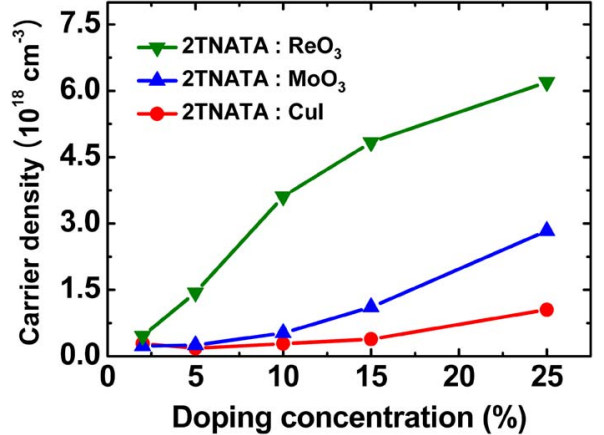

FIG. 4. (Color online) Carrier density vs doping concentration for $\mathrm{ReO}_{3}$ (inverse triangle), $\mathrm{MoO}_{3}$ (triangle), and CuI (circle) doped 2TNATA films.

characteristics of the formation of CT complexes [Fig. 1(b)] are very similar to the characteristics of the carrier density generated by the dopants (Fig. 4) as expected, indicating close relationship between the optical properties and the electrical properties of the doped films. More detailed mechanisms about the influence of $\Delta E$ on the formation of $\mathrm{CT}$ complexes and the ionization of CT complexes are under further investigation.

In summary, we investigated the effectiveness of $p$-dopants in the formation of CT complexes and in generating charges by paying attention to the energy difference between the HOMO level of organic materials and Fermi energy level of $p$-dopants. Through the FT-IR, UV-Vis-NIR spectroscopic measurements, the $J-V$, and the $C-V$ electrical measurements, we clearly demonstrated that dopants with higher work functions are more effective $\left(\mathrm{ReO}_{3}>\mathrm{MoO}_{3}\right.$ $>\mathrm{CuI})$ in the formation of $\mathrm{CT}$ complexes and in the generation of the holes in the doped films.

The authors are grateful to the Ministry of Knowledge Economy (MOKE) of Korea for financial support of this work. This work was also partially supported by the Samsung SDI and Dongwoo Finechem Co.
${ }^{1}$ J. Kido and T. Matsumoto, Appl. Phys. Lett. 73, 2866 (1998).

${ }^{2}$ G. He, M. Pfeiffer, K. Leo, M. Hofmann, J. Birnstock, R. Pudzich, and J. Salbeck, Appl. Phys. Lett. 85, 3911 (2004).

${ }^{3}$ T. Hasegawa, S. Miura, T. Moriyama, T. Kimura, I. Takaya, Y. Osato, and H. Mizutani SID Int. Symp. Digest Tech. Papers 35, 154 (2004).

${ }^{4}$ D.-S. Leem, S.-Y. Kim, J.-J. Kim, M.-H. Chen, and C.-I. Wu, Electrochem. Solid-State Lett. 12, J8 (2009).

${ }^{5}$ D.-S. Leem, J.-H. Lee, J.-J. Kim, and J.-W. Kang, Appl. Phys. Lett. 93, 103304 (2008).

${ }^{6}$ X. Zhou, M. Pfeiffer, J. Blochwitz, A. Werner, A. Nollau, T. Fritz, and K. Leo, Appl. Phys. Lett. 78, 410 (2001).

${ }^{7}$ C. Ganzorig and M. Fujihira, Appl. Phys. Lett. 77, 4211 (2000).

${ }^{8}$ J. Endo, T. Matsumoto, and J. Kido, Jpn. J. Appl. Phys., Part 2 41, L358, (2002).

${ }^{9}$ J.-H. Lee, D.-S. Leem, and J.-J. Kim, Org. Electron. 9, 805 (2008).

${ }^{10}$ X. L. Zhu, J. X. Sun, H. J. Peng, Z. G. Meng, M. Wong, and H. S. Kwok, Appl. Phys. Lett. 87, 153508 (2005).

${ }^{11}$ C.-C. Chang, M.-T. Hsieh, J.-F. Chen, S.-W. Hwang, and C. H. Chen, Appl. Phys. Lett. 89, 253504 (2006).

${ }^{12}$ T. Matsushima and C. Adachi, J. Appl. Phys. 103, 034501 (2008).

${ }^{13}$ H. Ikeda, J. Sakata, M. Hayakawa, T. Aoyama, T. Kawakami, K. Kamata, Y. Iwaki, S. Seo, Y. Noda, R. Nomura, and S. Yamazaki, SID Int. Symp. Digest Tech. Papers 37, 923 (2006).

${ }^{14}$ D.-S. Leem, H.-D. Park, J.-W. Kang, J.-H. Lee, J. W. Kim, and J.-J. Kim, Appl. Phys. Lett. 91, 011113 (2007).

${ }^{15}$ I. D. Baikie, U. Peterman, B. Lägel, and K. Dirscherl, J. Vac. Sci. Technol. A 19, 1460 (2001).

${ }^{16}$ T. Matsushima, Y. Kinoshita, and H. Murata, Appl. Phys. Lett. 91, 253504 (2007)

${ }^{17}$ A. R. Kumarasinghe, W. R. Flavell, A. G. Thomas, A. K. Mallick, D. Tsoutsou, C. Chatwin, S. Rayner, P. Kirkham, S. Warren, S. Patel, P. Christian, P. O'Brien, M. Grätzel, and R. Hengerer, J. Chem. Phys. 127, 114703 (2007).

${ }^{18}$ A. Salmerón-valverde, J. G. Robles-Martínez, J. García-Serrano, R. Gómez, R. M. Ridaura, M. Quintana, and A. Zehe, Mol. Eng. 8, 419 (1999).

${ }^{19}$ D. L. Pavia, G. M. Lampman, and G. S. Kriz, Introduction to Spectroscopy: A Guide for Students of Organic Chemistry (Brooks/Cole, Belmont, MA, 2001).

${ }^{20}$ E. J. Meijer, A. V. G. Mangnus, C. M. Hart, D. M. de Leeuw, and T. M. Klapwijk, Appl. Phys. Lett. 78, 3902 (2001).

${ }^{21}$ S. Grecu, M. Bronner, A. Opitz, and W. Brütting, Synth. Met. 146, 359 (2004).

${ }^{22}$ S. M. Sze, Physics of Semiconductor Device, 2nd ed. (Wiley-Interscience, New York, 1981). 